\title{
Artificial-neural-network-based model predictive control to exploit energy flexibility in multi-energy systems comprising district cooling
}

\author{
Gianluca Coccia $^{1, *}$, Alice Mugnini ${ }^{1}$, Fabio Polonara ${ }^{1,2}$, Alessia Arteconi ${ }^{3,1}$ \\ ${ }^{1}$ Università Politecnica delle Marche, Dipartimento di Ingegneria Industriale e Scienze \\ Matematiche, Via Brecce Bianche 12, 60131, Ancona, Italy \\ ${ }^{2}$ Consiglio Nazionale delle Ricerche, Istituto per le Tecnologie della Costruzione, Viale \\ Lombardia 49, 20098, San Giuliano Milanese (MI), Italy \\ ${ }^{3}$ KU Leuven, Department of Mechanical Engineering, B-3000, Leuven, Belgium \\ *Corresponding author: g.coccia@staff.univpm.it
}

\begin{abstract}
District cooling systems (DCSs) belonging to multi-energy systems can be managed by model predictive controls (MPCs) designed to reduce the amount of electrical energy collected from the grid for backup cooling systems when there is a temporal mismatch between energy demand and availability. In this paper, a DCS recovering cold thermal energy from a liquid-to-compressed natural gas fuel station is used in an 8-user residential neighborhood to provide space cooling in summertime. In the residential neighborhood, there is a multi-energy system, including the DCS, photovoltaic panels, and backup systems based on variable-load air-to-water heat pumps. One user of the district was allowed to manage its energy demand with an MPC based on an artificial neural network (ANN). By integrating the ANN-based MPC routine in the building simulation environment and unlocking the energy flexibility of thermostatically controlled loads (TCLs) using variable setpoints, it was possible to reduce electrical energy consumption up to $-71 \%$ with respect to a reference case with a rule-based control. This work highlights also the importance of the ANN training process for a proper representation of the TCL flexibility in the building model, which is not a trivial aspect to be taken into account in data driven models.
\end{abstract}


Keywords: liquefied natural gas; artificial neural network; district cooling; energy flexibility; predictive control

\section{Introduction}

The heating, ventilation, and air conditioning (HVAC) sector is responsible for a relevant part of the electrical energy demand, and it is expected to rise up to $4000 \mathrm{TWh}$ in 2050 [1]. Despite several solutions have been proposed to reduce peak demand in the air conditioning sector, such as demand side management (DSM) [2-4], new strategies need to be introduced to improve the overall efficiency and the recovery of different

energy sources managed in an aggregated way [5]. With different energy sources, we refer not only to traditional and renewable energy sources (RESs), but also to free waste energy that can be available from other processes.

An innovative technology able to fulfill the cooling demand in an efficient way, guaranteeing the possibility of mixing different energy sources, and even waste energy, is the district cooling system (DCS). DCSs allow a centralized management, production and distribution of cold thermal energy for space cooling. According to the EU Energy Efficiency Directive [6] and the Strategic Energy Technologies Information System [7], DCSs are considered among the best available technologies in the European Union and a strategic solution to achieve an increase of energy efficiency. DCSs are very flexible

and can be easily integrated with multi-energy systems such as renewable energy sources (RESs), trigeneration systems, and thermal energy storages (TESs) [8,9]. Among the possible energy sources, waste cold energy derived from commercial, transport, and industry sector represents an important opportunity and would allow to reduce the consumption of primary energy considerably by realizing sectors coupling. When DCSs supply cold thermal energy to a residential district, there are architectural bounds and queues to respect. For instance, the geographical position of the user in the network can affect the service received. Additionally, there could be circumstances when the waste energy available in the DCS is not sufficient to meet the cooling demand. There is therefore a need of backup systems such as chillers and heat pumps. However, these systems will likely operate in the season with maximum production 
from RESs as photovoltaic (PV) plants, that could be used to reduce the electricity collected from the grid.

In this kind of scenario, where the goal is to use free energy sources as much as possible, and at the same time to reduce the overall primary energy consumed by the multi-energy system, a key role is played by the flexibility of the energy system. In buildings and districts, energy flexibility is a property of the system that can be controlled for given purposes [10-12]. Buildings can supply flexibility in different ways, e.g. through their thermal mass, or by adjusting the HVAC control. A way to unlock energy flexibility in a building lies in the use of model predictive controls (MPCs). MPCs are smart control systems that can help managing the different sources available in a multi-energy system [13-15]. The use of MPCs allows to include, in the assessment of the control actions, forecasts defined in a certain prediction horizon. Forecasts can refer to price, weather, but also to energy sources availability as well as energy demand. If the optimization algorithm of the MPC properly evaluates the energy interactions between the sources and is able to unlock the energy flexibility of the building, there is the possibility to meet the space cooling demand of a residential user with a minimum absorption of electrical energy from the grid.

The representation of the building demand in the MPC can be based on a white, grey, or black box model. The first model is an accurate, physical representation of the system under study. It generally leads to the best results, but it can be difficult to retrieve all the needed information. A grey box model, instead, combines a partial theoretical structure with external parametric data that complete the model itself. Finally, a black box model consists only in a mathematical representation of the system, where each parameter of the model does not assume any physical meaning. In this case, the parameters of the model are determined by means of a training based on a data-driven approach.

Peculiar examples of black box models are artificial neural networks (ANNs), mathematical models that transform a set of input variables into a set of output variables [16]. ANNs are inspired to the functioning of a biological brain: the dendrites of a biological network correspond to the inputs of an ANN, while the output of an ANN performs the same task of a biological axon. The calculation nodes of an ANN are referred to as neurons, in the same fashion of a biological brain. In an $\mathrm{ANN}$, neurons 
are activation functions that operate on the inputs as linear or non-linear functions and provide the corresponding outputs. An ANN needs to be trained before use. The training process requires a proper dataset of inputs and targets, which will be used to find the weight values of the ANN calculation nodes. With the growing availability of big data and the promising possibilities offered by data science [17], data mining and machine learning [18], ANN-based MPCs used in the building sector have the opportunity to improve the prediction capabilities in multi-energy systems and their overall efficiency.

Referring to the existing literature, a comprehensive study of ANN-based MPCs using the flexibility of a building to optimize the management of a multi-energy system including free energy sources, such as waste thermal cold energy from a DCS or RESs, is difficult to be found. In the following, we will thus discuss relevant papers related to three different fields: 1) DCSs and their techno-economical optimization; 2) MPCs based on black box models and used in the building sector; 3) MPCs used in either district heating or cooling systems. The following paragraphs gather the works that belong to each specific field.

Starting from the literature concerning DCSs (point 1), in 2007 Chan et al. [19] proposed a genetic algorithm based on local search techniques to find the optimal configuration of a DCS piping network. It was found that the frequency of local search had no clear effect on the performance of the genetic algorithm optimization for the piping network. In 2016, Oh et al. [20] discussed a long-term electricity consumption forecasting model for buildings served by DCS technology. The authors modeled an innovative adsorbent-based dehumidifier and an indirect evaporative cooling technology, using a multiple linear regression model to forecast electricity demand for the period 2014-2030. Results indicated that the high conservative scenario realizes the best potential of electricity saving of 21'096 GWh until 2030 in Singapore, with an overall carbon footprint saving equal to about $9491 \mathrm{t}$. In the paper by van der Heijde et al. [21], the mathematical and software implementation in Modelica of a thermohydraulic model for district heating and cooling systems was discussed. The authors found good correspondence between experimental data from a controlled test setup and the model. In 2018, Vandermeulen et al. [22] investigated the flexibility obtainable from district heating and cooling systems. The authors highlighted that an important source of flexibility is represented by the thermal energy storages present in district 
heating and cooling networks, found for example in the thermal inertia of buildings, storage units and the network. They proposed a definition of flexibility and highlighted that more advanced control strategies are needed to fully unlock the flexibility of district heating and cooling systems. Dorotić et al. [23] reported that, due to their high interconnectivity and number of involved technologies, optimization of heating and district cooling systems represents a challenging task. In their work, they developed an hourly based multi-objective optimization model based on two objective functions to be minimized: total system cost (investments and operational) and carbon dioxide emissions. Based on results, it was proved that, for the same level of carbon dioxide emissions, combined district heating and cooling systems had lower total cost with respect to district systems operating separately. In their paper published in 2020, Arabkoohsar and Sadi [24] proposed a solar-driven absorption chiller, based on parabolic trough collectors, used to supply district heating and cooling. The solution was analyzed for a year and the authors found that it offered a significant contribution to supply the district heating demand, e.g. the heat demand of the chiller was determined to be zero for one-third of the year. Sun et al. [25] analyzed the performance of three district heating and cooling systems working with absorption and compression chillers driven by waste heat of flue gas, derived from coke ovens. The authors determined that the first configuration (including a single and a double-effect absorption chiller, a plate heat exchanger, a compression chiller for ice thermal energy storage, and a liquid desiccant regenerator) had both the highest thermodynamic performance and the best financial benefit. In the paper by Sommer et al. [26], it is stated that networks used for simultaneous heating and cooling are a key technology to decarbonize cities. In particular, the authors present the concept of reservoir network, which provides hydraulic decoupling of transfer stations, integrates heat sources and sinks at different temperature levels, and is modular. A single-pipe reservoir network was therefore compared to a conventional double-pipe network; it was found that the electric energy consumed by the two systems differs by less than $1 \%$ and that the reservoir network is more economical than other topologies if a ring layout is used. According to Jangsten et al. [27], DCSs will become more common in cities as the cooling demand increases. The authors also highlighted that performance of such systems is often penalized by low temperature differences between supply and return water. Thus, they analyzed 
operational data from both district cooling provider and chilled water systems used in buildings. Results indicate that low delta temperatures are mainly caused by low chilled water return temperature, low temperature approach of the heat exchangers and nonoptimized supply temperatures in the buildings. Sustainability, performance, and cost savings of DCSs were studied and improved by Anderson et al. [28] for a case study referred to University of Idaho. The authors carried out an exergy analysis with TRNSYS and the three objectives were achieved without equipment change. Specifically, electricity consumption was reduced to $38 \%$, with a correspondent saving of $428^{\prime} 800 \mathrm{~kg}$ of carbon dioxide emissions, and an annual cost saving of 140'000 USD was obtained.

As regards the use of MPCs based on black box models in the building sector (point 2), in 2012 Ferreira et al. [29] proposed a discrete MPC that used radial basis function ANNs as predictive models. The feasibility of the model was demonstrated with experimental results obtained in a building of University of Algarve. Results showed energy savings greater than $50 \%$. Similar results were expected to be obtained in the work presented by Ruano et al. [30] in 2016. In 2017, a supervisory controller based on an MPC logic was proposed by Afram and Janabi-Sharifi [31] to shift the heating and cooling demand of a residential building to off-peak hours. Experimental data obtained by an archetype house showed that the employment of variable temperature setpoints calculated by the MPC led to $16 \%$ cost savings respect to fixed setpoints. MPCs were also used to carry out an online energy optimization of a residential building with electric underfloor heating system [32]. Two control systems were considered: an MPC with constant temperature setpoint, and an MPC working with a setpoint optimizer able to minimize the amount of energy used. The first strategy led to a reduction of around $1430 \mathrm{kWh}$ during the heating season, while the second strategy allowed a further reduction of $300 \mathrm{kWh}$ in a year.

Focusing now on studies that propose the use of MPCs in district heating or cooling systems (point 3), an MPC strategy to meet the space heating demand of buildings connected to a district heating system was proposed by Aoun et al [33]. Results show that, compared to a conventional weather-compensation control, the MPC is costefficient and able to preserve a decent indoor thermal comfort level. Another work related to MPCs used in district heating systems was proposed by Saletti et al. [34], 
where an MPC was used to supply thermal energy in a school complex. Respect to a traditional PID controller, the MPC guaranteed a reduction in fuel consumption up to more than $7 \%$, and up to 5 hours of avoided failures of the indoor comfort constraints. Taking into account DCSs managed with MPCs and other similar controls, in 2019 Cox et al. [35] proposed an ANN-based MPC coupled with a genetic algorithm optimizer to determine the control strategy of an ice storage installed in a DCS. Results show that the optimal control can reduce the operating costs of the DCS by around $16 \%$ and $13 \%$ under a time-of-use and a real-time pricing, respectively. In their work published in 2020, Lyons et al. [36] highlighted the need to improve energy flexibility integration between district heating systems and the power grid. Thus, a model reduction technique based on Hankel Singular Value Decomposition was used to reproduce an extended district of buildings. The approach was tested in both centralized and decentralized systems in terms of comfort and cost and demonstrated the need to consider the ability of buildings to interact within a wider system in order to completely realize the potential benefits of intelligent MPCs. According to De Lorenzi et al. [37], it is hard to find in literature comprehensive frameworks for the integrated setup of smart control strategies coupled with new generation district heating and cooling systems. The authors therefore proposed a framework that involves all steps of a controller development (based on an MPC) for small-scale district networks. It was found that, compared to conventional controls, smart solutions achieved $6 \%$ reduction in cost and up to $34 \%$ reduction in energy consumption.

As can be noted from the analysis of the literature, MPCs based on black box models (e.g., ANNs) and used in buildings have been considered and found relevant. However, based on the knowledge of the authors, the issues related to the use and training of ANNs in MPCs and their implementation in multi-energy systems were not investigated in detail in case that the energy flexibility of thermostatically controlled loads (TCLs) wants to be unlocked. Indeed, if a black box building model needs to take into account the TCL energy flexibility, a critical aspect lies in the selection of an adequate dataset, which should contain data able to represent the effect of flexibility between the controlled variables (indoor and outdoor temperatures, thermal gains, etc.) and the output of the model (e.g., cooling demand). Thus, it is important to train the ANN with a dataset that already accounts for the effects of flexibility in the building, even if it is 
not trivial given the large amount of possible configurations; otherwise, the ANN would not be able to simulate such effects. Additionally, in multi-energy systems that use energy flexibility, the interaction and the prioritization of the available energy sources need to be carefully analyzed. In fact, several issues arise when the goal is the development of an MPC able to unlock the building flexibility in order to minimize the electrical energy consumption; in this paper, we will see that it may be impossible to propose a general mathematical formulation for the MPC, and that specific cases should be examined and solved. Given the importance that multi-energy systems could have in the current and future energy scenario, in this work we investigated an application of multi-energy system including a DCS, RESs (PV modules) and backup systems based on variable-load air-to-water heat pumps (AWHPs). In the residential neighborhood served by the DCS, one user was allowed to be managed by an ANN-based MPC having the goal to reduce the electricity absorbed from the grid using the energy flexibility of the building. Flexibility was unlocked by the supervisory MPC, that imposed optimal variable setpoints to the local controllers. The work focuses on the importance that energy flexibility assumes both in the training of black box models and in its effect in MPCs used to manage thermal comfort of buildings. A specific mathematical approach was therefore proposed for the considered case study, approach that can be also used in different multi-energy systems.

The paper is organized as follows. Section 2 describes the methodology followed to develop the ANN-based MPC and to evaluate its performance. The case study is described in Section 3. In this section, the MPC formulation, its basic assumptions and its integration in the simulation environment are discussed in detail. The results and discussion of the analysis are provided in Section 4. Section 5 reports the conclusions of the study.

\section{Methodology}

The smart management of a multi-energy system based on sources of different nature (waste, RESs, fossil) can lead to a significant primary energy saving if its subsystems are able to interact with each other under the supervision of a high-level MPC. To be 
really effective, the MPC should be able to estimate within a useful prediction horizon the availability of RESs and potential free sources such as waste energy, as well as the energy demand of the system. To reach this goal, the MPC must rely on a model representing the system under study. As outlined in the Introduction, the use of a black box model based on an artificial neural network (ANN) allows, respect to theoretical models (white and grey box models), to take advantage of the larger and larger availability of big data, and to perform a continuous improvement of the model itself. This is the reason why in this work we decided to focus our attention on an ANN-based MPC. Once reliable prediction data are available, an appropriate prediction horizon should be selected. While there is no general rule to choose the optimal prediction horizon, it is important to note that a too short prediction horizon could lead to a poor performance of the MPC because its field of action is too limited. On the other hand, a too long prediction horizon could be unreliable, as prediction data always have some extent of uncertainty. For this reason, the effect related to the choice of the prediction horizon extent will be discussed in the results of this study (Section 4).

The goal of the MPC discussed in this study is to reduce the electricity taken from the grid by a multi-energy system consisting of a DCS, photovoltaic (PV) panels, and backup systems based on variable-load air-to-water heat pumps (AWHPs). The DCS uses waste cold thermal energy recovered from a liquid-to-compressed natural gas (LCNG) fuel station [38], while the AWHPs can absorb electrical energy from either the grid or from the dedicated PV modules. As can be noted, the system presents a mix of different energy sources: a RES (the PV plant), a free waste source (the cold thermal energy provided by the DCS), and a traditional source (the electricity collected from the grid, which derives from non-renewable sources for the most part). The multienergy system is used to satisfy the cooling energy demand of a residential neighborhood composed by 8 single-family houses. Each house is connected to the DCS and has a dedicated PV plant and AWHP. In the reference case, which we will refer to as baseline, the multi-energy system relies on the instantaneous availability of the PV modules and of the waste cold thermal energy supplied by the DCS, compensating the possible energy deficit through the electricity absorbed from the grid. In the baseline, there is no possibility to exploit the energy flexibility of the building, 
as the local control is a traditional thermostat working within a fixed indoor temperature band $\left(25.5 \pm 0.5^{\circ} \mathrm{C}\right)$, which provides the design thermal comfort level.

In order to evaluate its performance, in this work the ANN-based MPC was allowed to operate in one of the houses of the residential district, using the flexibility given by the indoor temperature of the building. Compared to the baseline, the ANN-based MPC operates as a supervisory control that communicates, at each time step of one hour, a variable setpoint to the local building control. The interaction between the ANN-based MPC and the multi-energy system will be presented in Section 3.4, and it is schematized in Figure 11. Since the use of a variable setpoint could worsen the design thermal comfort level, in Section 4 the predicted mean vote $(P M V)$ for both the cases was also reported, in order to check the satisfaction of a minimum comfort quality.

\section{Case study}

The case study consists of an 8-user residential neighborhood which has a cooling demand to be satisfied in summertime. Figure 1 shows the plant scheme of the case study. As can be seen, the cooling demand of each user can be satisfied either through the free waste cold thermal energy provided by the DCS, or through the activation of a variable-load air-to-water heat pump (AWHP). The heat pump can use electrical energy drawn either from the grid or, when available, from dedicated PV modules. The cooling power available in the DCS network is recovered from the LNG vaporizer of a nearby L-CNG refueling station. 

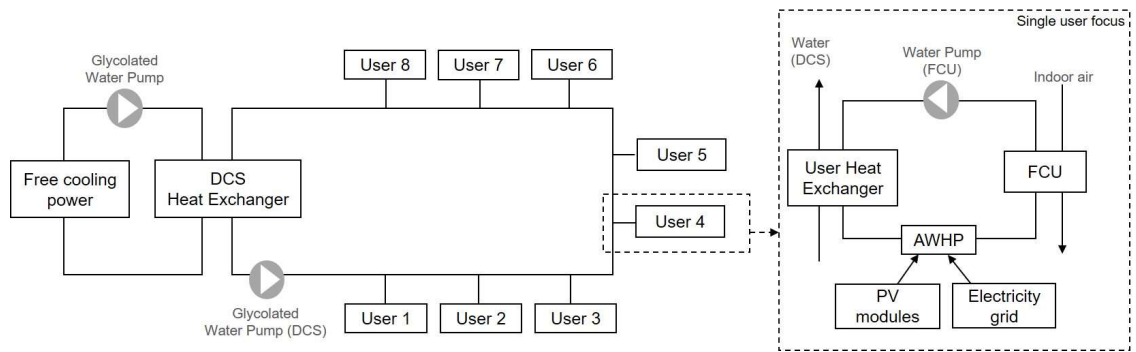

Figure 1. Plant scheme of the energy system under study, with a focus on the single-user configuration. The cold thermal energy recovered from the L-CNG vaporizer is used to fulfill a residential DCS.

\subsection{L-CNG cooling recovery}

Given the relevance of alternative fuels for vehicles and the interconnection between the transportation and residential sector within urban areas, the waste cold is supposed to be recovered from a L-CNG refueling station [38]. To evaluate its cooling power profile, we started from data reporting the CNG sold in a L-CNG station for the vehicle

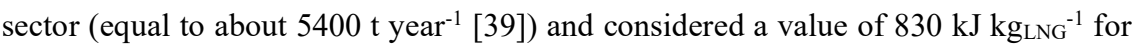
the energy released during the LNG evaporation [40]; in this way, $380 \mathrm{kWh}^{-1} \mathrm{day}^{-1}$ was found to be the potential cold energy availability per day in a L-CNG refueling plant.

Additionally, considering a typical probability distribution profile of a daily $\mathrm{CNG}$ refueling operation [41], the cooling power profile shows a trend as that depicted in Figure 2. The profile provided in Figure 2 was therefore selected as the cooling supply side availability for the DCS. The available cold thermal energy is supplied to the DCS network by means of a heat exchanger ("DCS Heat Exchanger" in Figure 1). Both the primary and the secondary circuits use a water-glycol mixture as heat transfer fluid; in the former, the cold fluid is supposed to be available at a temperature of $-15^{\circ} \mathrm{C}$, while the temperature of the latter is $-5^{\circ} \mathrm{C}[42]$. 


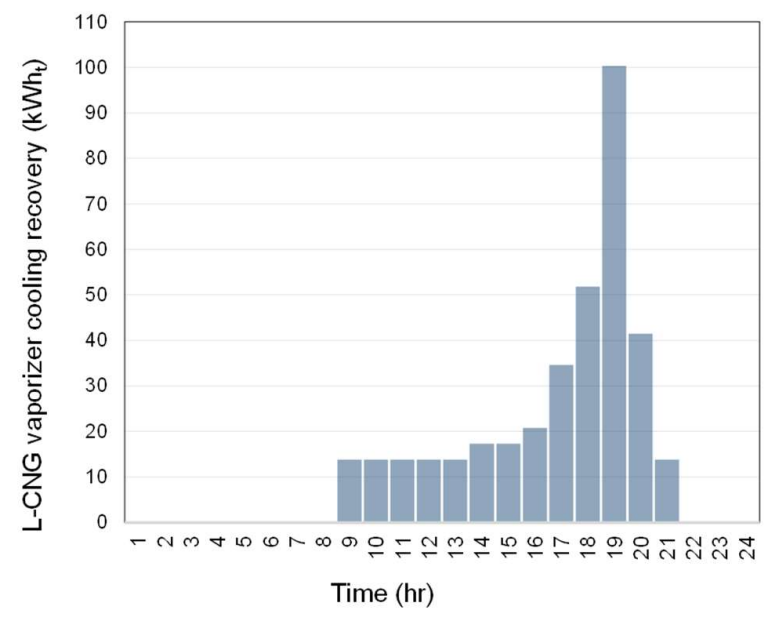

Figure 2. Hourly cold energy recovery from a typical L-CNG vaporizer in a fuel station.

\subsection{District cooling system and residential neighborhood}

Referring to Figure 1, the actual DCS network starts from the "DCS Heat Exchanger". The pipes used in the network modeling are insulated and installed underground [43]. As for the model proposed in [38], the pipe diameters were chosen to maintain the fluid velocity in an acceptable range $\left(1.5-2 \mathrm{~m} \mathrm{~s}^{-1}\right.$ for the main branches and around $1 \mathrm{~m} \mathrm{~s}^{-1}$ for the connections with the users [44]).

The residential district connected to the DCS is composed of 8 single-family-house users located in Rome, Italy $\left(41^{\circ} 55^{\prime} \mathrm{N}, 12^{\circ} 31^{\prime} \mathrm{E}\right)$. The thermal characteristics of the buildings envelope were extrapolated from the Tabula Project [45]. Each building was modelled as a single thermal zone with a simple lumped capacitance structure described by an overall building loss coefficient $\left(0.38 \mathrm{~W} \mathrm{~m}^{-2} \mathrm{~K}^{-1}\right)$ and a total thermal capacitance (55 $\left.\mathrm{MJ} \mathrm{K}^{-1}\right)$ [46].

The number of users included in the neighborhood was determined by first estimating the single user design cooling load [47]: the peak demand was determined to be $6.7 \mathrm{~kW}_{\mathrm{t}}$, with an indoor comfort condition of $26{ }^{\circ} \mathrm{C}$ and $50 \%$ relative humidity. Then, it was assured that the cold thermal energy recovered by the L-CNG vaporizer was able to meet 
the peak cooling demand of each user for at least two hours per day: this led to a number of 8 users to be served by the DCS, as can be seen from Figure 3 .

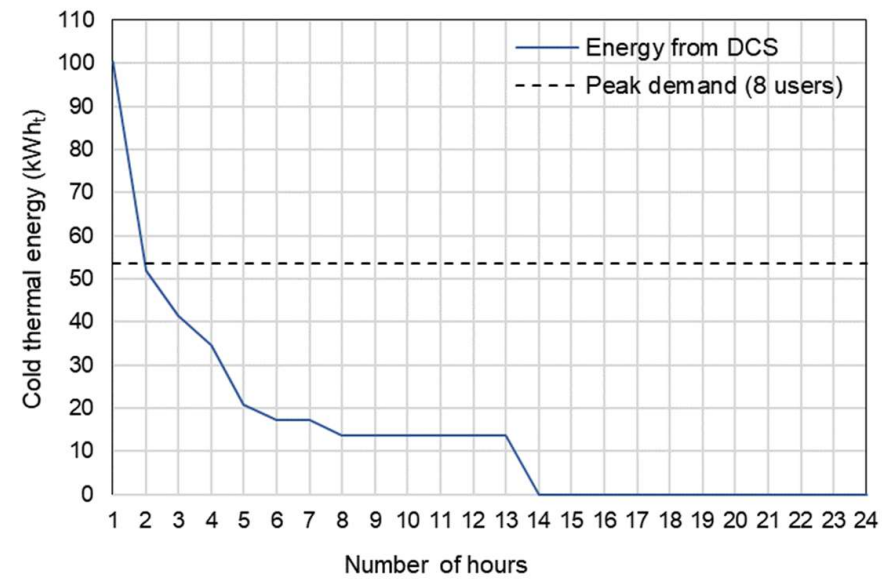

Figure 3. Duration curve of the cold thermal energy provided by the L-CNG vaporizer.

The connection between the DCS network and each user was realized through a heat exchanger ("User Heat Exchanger", Figure 1) in which the DCS heat transfer fluid cools water down to a temperature of $7{ }^{\circ} \mathrm{C}$, if the peak cooling demand is satisfied. When the cold thermal energy provided by the DCS is not sufficient, the cooling demand can be covered by backup systems installed by each individual user. The backup systems consist of variable-load air-to-water heat pumps (AWHPs), whose coefficient of performance $(C O P)$ curve was determined with a regressive linear model that correlates outdoor temperature, fluid delivery temperature and load [48]. The COP curves of the AWHP are plotted in Figure 4. Each AWHP is connected in series with the "User Heat Exchanger", as shown in Figure 1, and it can be switched on by a controller set on the comfort limit of the indoor temperature $\left(25.5+0.5^{\circ} \mathrm{C}\right)$. Fan coil units (FCUs) were used to transfer the available cooling power from the water circuit to the indoor air. 


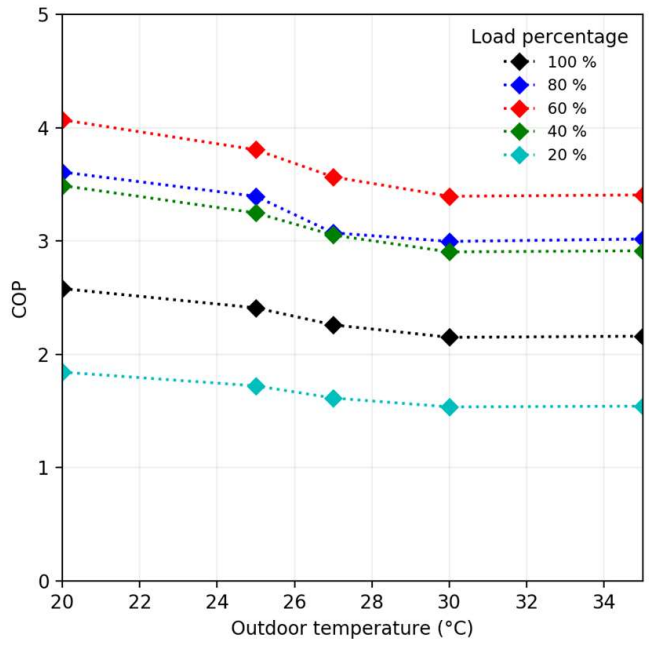

Figure 4. $C O P$ curves of the AWHP (for a fluid delivery temperature of $7^{\circ} \mathrm{C}$ ).

The AWHPs can be powered by the electricity collected from either the grid or PV modules installed on the roof of each building. Each PV plant is composed of 3 arrays, and each array includes 10 polycrystalline-silicon panels connected in series with a nominal peak power of $250 \mathrm{~W}_{\mathrm{e}}$ [49]. The power output of the PV plant, for a typical summer week in Rome, Italy, is reported in Figure 5.

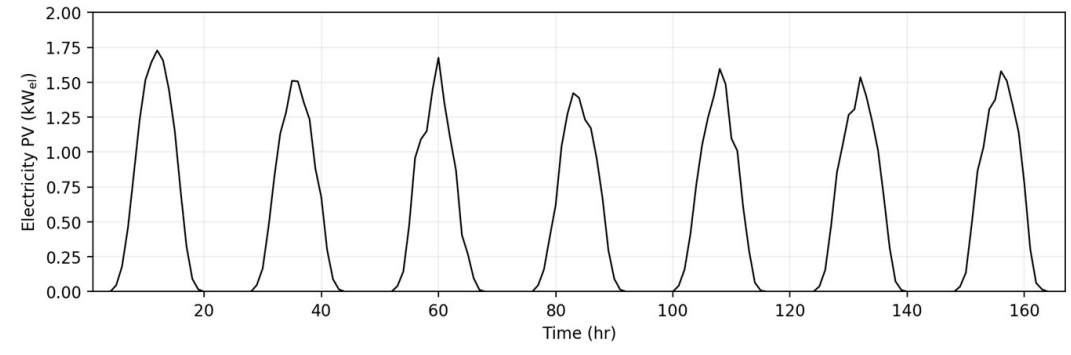

Figure 5. Electrical power output of the PV plant. 
The DCS and the residential neighborhood were modeled in a TRNSYS simulation environment. Specifically, each building was modeled with Type 88, the heat exchangers with Type 5, the FCUs with Type 996, and the PV plants with Type 194.

\subsection{ANN for the evaluation of the cooling demand}

In the present study, the prediction data of the sources (i.e., the PV production and the waste cold thermal energy provided by the DCS) are supposed to be well-defined for the MPC, together with the outdoor temperature and the thermal gains of the building. The estimation methods of these sources have been discussed in Section 3.1 and 3.2. Here, the focus is on the prediction of the cooling demand required by one of the houses in the residential neighborhood.

As introduced in Section 2, an ANN used in an MPC to predict the cooling demand can be trained with a large amount of data, deriving from either experimental measures or numerical evaluations. Before training, however, it is important choosing the best ANN architecture that represents the system in exam under a logical-mathematical point of view. In the baseline, the cooling demand of one single-family house is being satisfied with a variable-load AWHP managed by a traditional local control, which is based on a ON/OFF logic. In this case, the heat pump works always near the design nominal capacity, equal to $6.7 \mathrm{~kW}_{\mathrm{t}}$. In other words, the modeling of the cooling demand basically consists in determining when the building needs to be cooled, and this can be regarded as a Boolean problem. The most appropriate ANN to choose in this case is therefore an architecture dedicated to classification problems.

In MATLAB, which we used to train and run our network, the ANNs used to solve classification problems are referred to as pattern recognition networks. Pattern recognition networks are feedforward networks that can be trained to classify inputs according to the target classes. To reduce the classification errors of the network, it is important to train the ANN with a proper dataset. The main variables influencing the cooling demand were therefore investigated: indoor setpoint temperature (Figure 6), outdoor temperature (Figure 7), and building thermal gains (Figure 8). Among these variables, the most relevant input is the indoor setpoint temperature, which strongly influences the thermal 
behavior of the building. The next, important step involves the selection of the hourly data, and their number, to be used to train the ANN. A too small dataset, in fact, could lead to a poor general interpolating performance of the network. Too many data, on the other hand, could result in an overfitting of the problem. Overfitting intensifies the interpolating capacity of the network, thus resulting in a poor representation of the output when new data are provided to the ANN. To avoid overfitting, only 500 normalized hourly data for the cooling demand ( $Q_{\text {build }}$ ) in the month of July were considered for the dataset (Figure 9). However, these data, obtained through the TRNSYS simulation environment representing the baseline configuration, were not based on a fixed indoor setpoint temperature. In fact, this would have led to a very poor performance prediction of the ANN, which would have not been able to learn the trend of the building cooling demand at different setpoint temperature values. As a result, this would have deteriorated the use of the energy flexibility provided by the building. To overcome this issue, the TRNSYS simulation environment was allowed to work at different indoor setpoint temperatures $\left(24.5,25.5,26.5,27.5^{\circ} \mathrm{C}\right)$, variable on a daily basis (a different setpoint every day, as represented in Figure 6). In this way, it was possible to evaluate the cooling demand trend of the building at variable setpoint temperatures, and the data provided by this peculiar simulation environment were finally used to build the definitive training dataset of the ANN. To further reduce the possibility of overfitting issues, the definitive dataset was also randomly subdivided into a training set (50\%), a validation set $(30 \%)$, and a test set $(20 \%)$. The validation set was used, during the error minimization routine, to check if overfitting occurred and to stop the training if necessary. The test set, instead, was used to evaluate the performance of the trained ANN. 


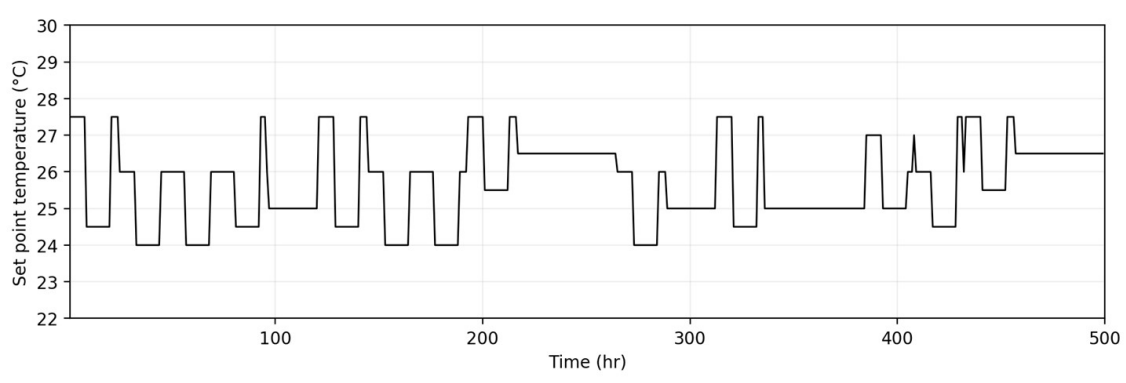

Figure 6. Indoor setpoint temperature data used to train the ANN.

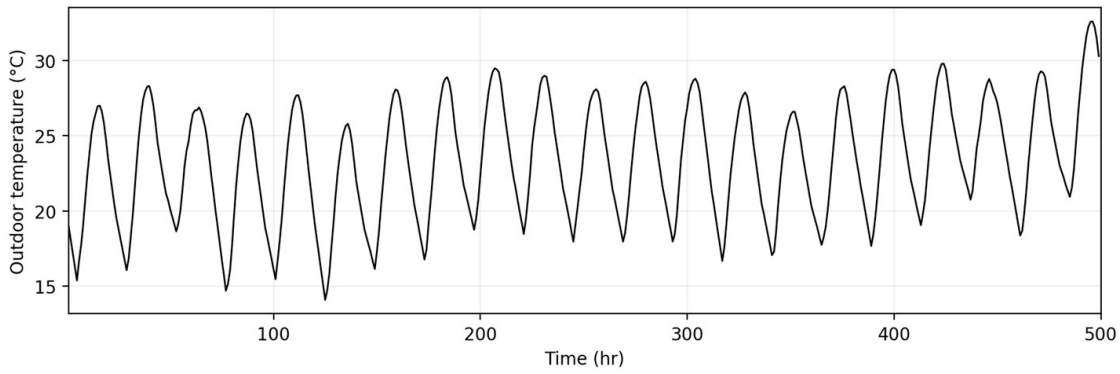

Figure 7. Outdoor temperature data used to train the ANN.

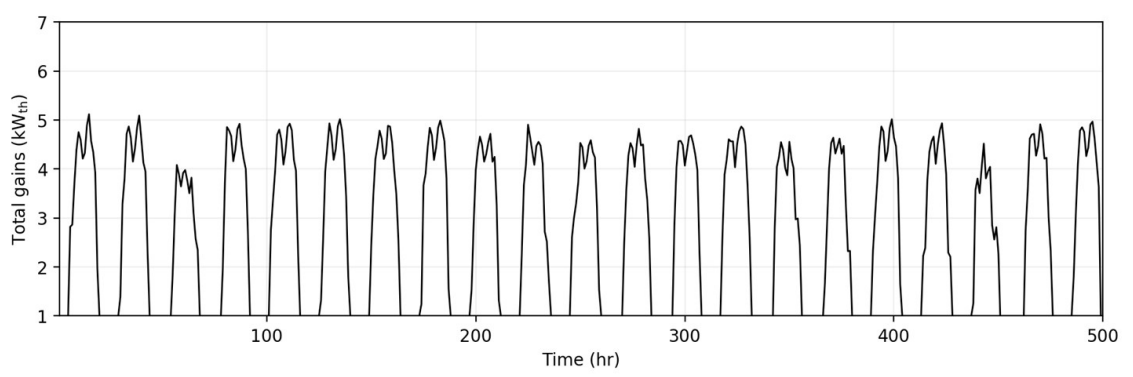

Figure 8. Thermal gains data used to train the ANN. 


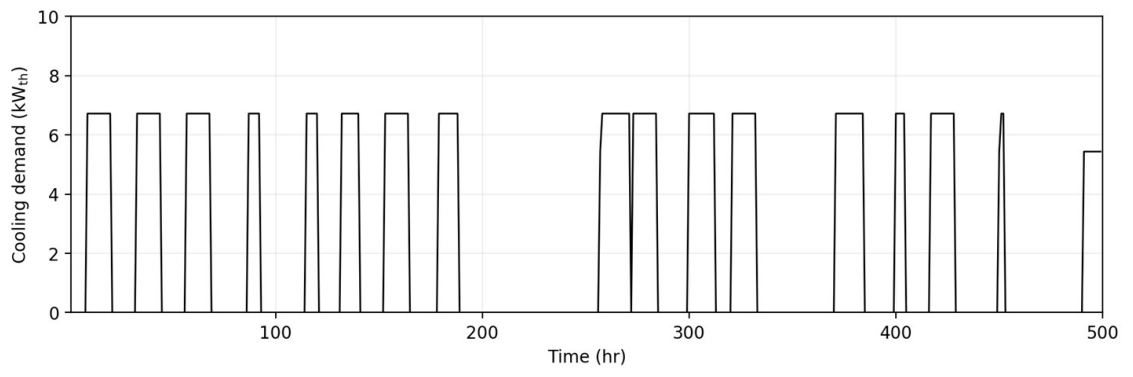

Figure 9. Cooling demand ( $\left.Q_{\text {build }}\right)$ data used to train the ANN.

Additional precautions were taken to avoid overfitting by selecting an appropriate number of neurons and layers of neurons. Since it was demonstrated [11] that even one hidden layer of neurons is sufficient to fit complex, non-linear problems, the ANN used in this study consists of one hidden layer with 10 neurons (Figure 10), which are a good tradeoff between performance of the network and overfitting of the data. The activation function used in the hidden layer was a sigmoid, while the activation function used in the output layer was a softmax [50]. The minimization algorithm chosen for the training of the network was the default scaled conjugate gradient backpropagation [51].

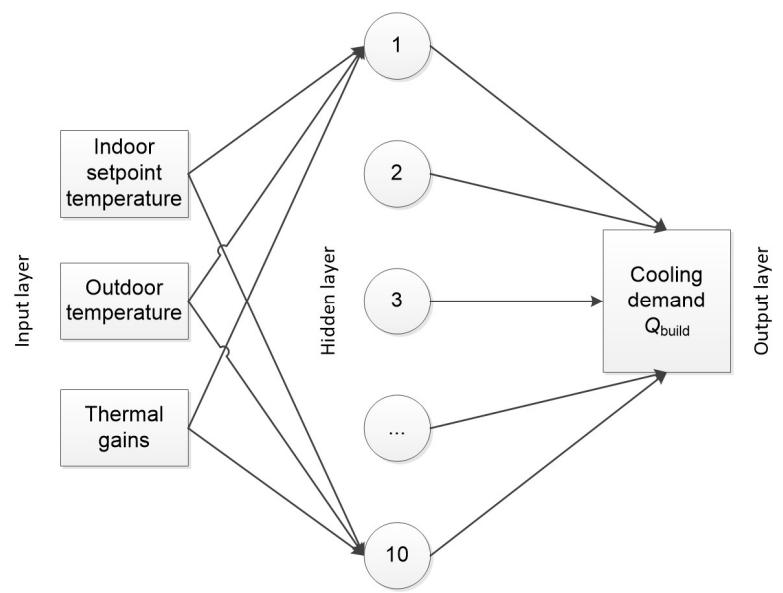

Figure 10. Pattern ANN architecture used to predict the cooling demand $Q_{\text {build. }}$ 
To evaluate the performance of the ANN, a cross-entropy approach [52] was used. Based on the results provided by the ANN model, the training, validation, test, and overall accuracy of the network were equal to, respectively, $96.0 \%, 94.7 \%, 90.0 \%$, and $94.4 \%$. Thus, it can be concluded that the cooling demand ( $\left.Q_{\text {build }}\right)$ estimated by the ANN is sufficiently accurate. However, it is worth remarking that, in order to obtain this result, data obtained with variable setpoints were needed, i.e. in some extent different from those of the baseline configuration.

\subsection{Integration of the MPC in the simulation environment}

Since the ANN allows to predict the cooling demand of a single-family house in the residential neighborhood, there is the possibility to design an ANN-based MPC able to use the demand prediction to minimize the electrical energy consumption of the building. Specifically, in the present study the MPC can minimize the electricity absorbed from the grid $\left(E_{\text {grid }}\right)$ by the backup AWHP installed in building. Along with the cooling demand, which is a function of the indoor setpoint temperature $\left(Q_{\text {build }}=\right.$ $\left.Q_{\text {build }}\left(T_{\text {set }}\right)\right)$, the MPC should be allowed to know the free energy sources available in the system in a certain prediction horizon, i.e. the waste cold thermal energy provided by the DCS $\left(Q_{\mathrm{DCS}}\right)$ and the electricity producible by the PV plant $\left(E_{\mathrm{PV}}\right)$, as well as the

coefficient of performance $(C O P)$ of the variable-load AWHP used in the building. If all these quantities are known, the MPC can process an energy minimization algorithm and determine an optimal indoor setpoint temperature $\left(T_{\text {set }}\right)$ according to the energy flexibility availability of the building. The optimization variable $T_{\text {set }}$ is not allowed to assume any possible value, but its domain is limited in the set of constraints $\{24.5,25.5$, $26.5,27.5\}^{\circ} \mathrm{C}$, in order to guarantee a thermal comfort level comparable to that of the baseline. Since the MPC supervises the local control, a $T_{\text {set }}$ resolution of $1{ }^{\circ} \mathrm{C}$ was used to reproduce the behavior of a traditional thermostat.

However, given the nature of the multi-energy system under study, the goal of the MPC is not limited at calculating an optimal setpoint temperature. In fact, based on the availability of the free sources in the chosen prediction horizon, the MPC should also 
evaluate for each time step if either the DSC or the AWHP are allowed to work in User 4 (Figure 1). In summary, the supervisory MPC should provide the local control unit with three data for each time step: an optimal indoor setpoint temperature $\left(T_{\text {set }}\right)$, a Boolean control for the heat exchange with the DCS (CTR $\left.L_{\mathrm{DCS}}\right)$, and a Boolean control for the functioning of the AWHP $\left(C T R L_{\mathrm{HP}}\right)$. While $T_{\text {set }}$ is the result of an energy minimization carried out for the whole prediction time, the selection of the two Boolean controls also depends on the actual availability of the free energy sources in the current time step under evaluation. In fact, there could be occurrences where there is no availability of the free sources in the current time step, even if they will become available in the following hours. In such a case, the Boolean controls determined by the MPC for the current time step should be $C T R L_{\mathrm{DCS}}=C T R L_{\mathrm{HP}}=0$. This trivial example highlights that the MPC cannot be based only on an energy balance referred to the chosen prediction horizon, but it is also necessary to carefully evaluate what happens in the first hour of the evaluation period, i.e. the current time step.

Based on the aforementioned considerations, there is no possibility to write a standalone objective function based on an energy balance equation and it is therefore necessary to subdivide the energy problem in cases. Let $Q_{\text {build }}$ be the cooling demand of the building for all the admissible values of $T_{\mathrm{set}}$ and $t_{\mathrm{PH}}$ be the chosen prediction horizon for the current time step $t$. The evaluation time is thus comprised in the period $\left[t, t+t_{\mathrm{PH}}\right]$. The MPC should evaluate the cases provided in Table 1. As will be noted, some of these cases result in trivial mathematical problems to be solved, where it is sufficient to select the highest admissible $T_{\text {set }}$ (i.e., $27.5^{\circ} \mathrm{C}$ ). Most of the cases, however, requires the definition of a proper energy objective function, $E_{\mathrm{grid}}\left[t, t+t_{\mathrm{PH}}\right]$, that must be minimized by the MPC optimization algorithm.

Table 1. Cases managed by the MPC routine.

\begin{tabular}{rll}
\hline Case & Equations & Comments \\
\hline 0 & $Q_{\text {build }}\left[t, t+t_{P H}\right]=0 ;$ & There is no cooling demand in the \\
& & current time step and in the whole \\
& $T_{\text {set }}\left[t, t+t_{P H}\right]=27.5^{\circ} C, C T R L_{D C S}[t]=0, C T R L_{H P}[t]=0$, & prediction horizon, for all the admissible \\
& $E_{\text {grid }}[t]=0$ & setpoint values \\
\hline
\end{tabular}




\begin{tabular}{|c|c|c|}
\hline 1 & $\begin{array}{l}Q_{\text {build }}[t]=0, Q_{\mathrm{DCS}}[t]=0, E_{\mathrm{PV}}[t]=0 \\
T_{\text {set }}\left[t, t+t_{\mathrm{PH}}\right]=27.5{ }^{\circ} \mathrm{C}, C T R L_{\mathrm{DCS}}[t]=0, C T R L_{\mathrm{HP}}[t]=0, \\
E_{\text {grid }}[t]=0\end{array}$ & $\begin{array}{l}\text { At the current time step, there is no } \\
\text { cooling demand and no free energy } \\
\text { source available }\end{array}$ \\
\hline 2 & $\begin{array}{l}T_{\mathrm{set}}\left[t, t+t_{\mathrm{PH}}\right]=T_{\mathrm{set}, \mathrm{min}}, \quad C T R L_{\mathrm{DCS}}[t]=0, \quad C T R L_{\mathrm{HP}}[t]=1, \\
E_{\text {grid }}[t]=0\end{array}$ & $\begin{array}{l}\text { At the current time step, there is no } \\
\text { cooling demand, but the photovoltaic } \\
\text { source is available. The optimal value of } \\
T_{\text {set }} \text { is chosen based on the minimization } \\
\text { of the energy objective function }\end{array}$ \\
\hline 3 & $\begin{array}{l}Q_{\text {build }}[t]=0, Q_{\mathrm{DCS}}[t] \neq 0, E_{\mathrm{PV}}[t]=0, \\
\text { find } T_{\mathrm{set}}\left[t, t+t_{\mathrm{PH}}\right] \text { so that } \\
E_{\text {grid }}\left[t, t+t_{\mathrm{PH}}\right]=\min \left(E_{\mathrm{grid}}\left[t, t+t_{\mathrm{PH}}\right]\right) \\
T_{\text {set }}\left[t, t+t_{\mathrm{PH}}\right]=T_{\mathrm{set}, \min }, \quad C T R L_{\mathrm{DCS}}[t]=1, \quad C T R L_{\mathrm{HP}}[t]=0, \\
E_{\text {grid }}[t]=0\end{array}$ & $\begin{array}{l}\text { At the current time step, there is no } \\
\text { cooling demand, but the waste cold } \\
\text { thermal energy provided by the DCS is } \\
\text { available. The optimal value of } T_{\text {set }} \text { is } \\
\text { chosen based on the minimization of the } \\
\text { energy objective function }\end{array}$ \\
\hline 4 & $\begin{array}{l}Q_{\text {build }}[t]=0, Q_{\mathrm{DCS}}[t] \neq 0, E_{\mathrm{PV}}[t] \neq 0, \\
\text { find } T_{\text {set }}\left[t, t+t_{\mathrm{PH}}\right] \text { so that } \\
E_{\text {grid }}\left[t, t+t_{\mathrm{PH}}\right]=\min \left(E_{\text {grid }}\left[t, t+t_{\mathrm{PH}}\right]\right) ; \\
T_{\text {set }}\left[t, t+t_{\mathrm{PH}}\right]=T_{\text {set,min }}, \quad C T R L_{\mathrm{DCS}}[t]=1, \quad C T R L_{\mathrm{HP}}[t]=1, \\
E_{\text {grid }}[t]=0\end{array}$ & $\begin{array}{l}\text { At the current time step, there is no } \\
\text { cooling demand, but both the free energy } \\
\text { sources are available. The optimal value } \\
\text { of } T_{\text {set }} \text { is chosen based on the } \\
\text { minimization of the energy objective } \\
\text { function }\end{array}$ \\
\hline 5 & $\begin{array}{l}T_{\mathrm{set}}\left[t, t+t_{\mathrm{PH}}\right]=27.5{ }^{\circ} \mathrm{C}, C T R L_{\mathrm{DCS}}[t]=0, C T R L_{\mathrm{HP}}[t]=1, \\
E_{\text {grid }}[t]=Q_{\text {build }}[t] / C O P[t]\end{array}$ & $\begin{array}{l}\text { At the current time step, there is cooling } \\
\text { demand for at least one value of } T_{\text {set }} \text {, but } \\
\text { both the free energy sources are not } \\
\text { available }\end{array}$ \\
\hline 6 & $\begin{array}{l}T_{\text {set }}\left[t, t+t_{\mathrm{PH}}\right]=T_{\text {set,min }}, C T R L_{\mathrm{DCS}}[t]=0, C T R L_{\mathrm{HP}}[t]=1, \\
E_{\text {grid }}[t]=Q_{\text {build }}[t] / C O P[t]-E_{\mathrm{PV}}[t] \text { if } \\
Q_{\text {build }}[t] / C O P[t]>E_{\mathrm{PV}}[t] \\
E_{\text {grid }}[t]=0 \text { if } Q_{\text {build }}[t] / C O P[t] \leq E_{\mathrm{PV}}[t]\end{array}$ & $\begin{array}{l}\text { At the current time step, there is cooling } \\
\text { demand for at least one value of } T_{\text {set, }} \text { and } \\
\text { the photovoltaic source is available. The } \\
\text { optimal value of } T_{\text {set }} \text { is chosen based on } \\
\text { the minimization of the energy objective } \\
\text { function }\end{array}$ \\
\hline 7 & $\begin{array}{l}Q_{\text {build }}[t] \neq 0, Q_{\mathrm{DCS}}[t] \neq 0, E_{\mathrm{PV}}[t]=0, \\
\text { find } T_{\text {set }}\left[t, t+t_{\mathrm{PH}}\right] \text { so that } \\
E_{\text {grid }}\left[t, t+t_{\mathrm{PH}}\right]=\min \left(E_{\text {grid }}\left[t, t+t_{\mathrm{PH}}\right]\right) ; \\
T_{\text {set }}\left[t, t+t_{\mathrm{PH}}\right]=T_{\text {set,min }}, C T R L_{\mathrm{DCS}}[t]=1, C T R L_{\mathrm{HP}}[t]=1,\end{array}$ & $\begin{array}{l}\text { At the current time step, there is cooling } \\
\text { demand for at least one value of } T_{\text {set }} \text {, and } \\
\text { the waste cold thermal energy provided } \\
\text { by the DCS is available. The optimal } \\
\text { value of } T_{\text {set }} \text { is chosen based on the }\end{array}$ \\
\hline
\end{tabular}




\begin{tabular}{lll}
\hline & $E_{\text {grid }}[t]=\left(Q_{\text {build }}[t]-Q_{\mathrm{DCS}}[t]\right) / C O P[t]$ if & minimization of the energy objective \\
& $Q_{\text {build }}[t]>Q_{\mathrm{DCS}}[t]$, & \\
& $E_{\text {grid }}[t]=0$ if $Q_{\text {build }}[t] \leq Q_{\mathrm{DCS}}[t]$ & \\
\hline 8 & $Q_{\text {build }}[t] \neq 0, Q_{\mathrm{DCS}}[t] \neq 0, E_{\mathrm{PV}}[t] \neq 0$, & At the current time step, there is cooling \\
& find $T_{\mathrm{set}}\left[t, t+t_{\mathrm{PH}}\right]$ so that & demand for at least one value of $T_{\text {set, }}$ and \\
& $E_{\text {grid }}\left[t, t+t_{\mathrm{PH}}\right]=\min \left(E_{\text {grid }}\left[t, t+t_{\mathrm{PH}}\right]\right) ;$ & both the free energy sources are \\
& available. The optimal value of $T_{\text {set is }}$ \\
& $T_{\text {set }}\left[t, t+t_{\mathrm{PH}}\right]=T_{\text {setmin }}, C T R L_{\mathrm{DCS}}[t]=1, C T R L_{\mathrm{HP}}[t]=1$, & chosen based on the minimization of the \\
& $E_{\text {grid }}[t]=\left(Q_{\text {build }}[t]-Q_{\mathrm{DCS}}[t]\right) / C O P[t]-E_{\mathrm{PV}}[t]$ if & energy objective function \\
& $\left(Q_{\text {build }}[t]-Q_{\mathrm{DCS}}[t]\right) / C O P[t]-E_{\mathrm{PV}}[t]>0$, & \\
& $E_{\text {grid }}[t]=0$ if $\left(Q_{\text {build }}[t]-Q_{\mathrm{DCS}}[t]\right) / C O P[t]-E_{\mathrm{PV}}[t] \leq 0$ & \\
\hline
\end{tabular}

The objective function that the MPC optimization algorithm must minimize is based on a general energy balance of the building, evaluated for the whole prediction horizon chosen. It can be written as:

$$
E_{\text {grid }}\left[t, t+t_{\mathrm{PH}}\right]=\sum_{i=t}^{t+t_{\mathrm{PH}}} E_{\text {grid }}[i]
$$

where, for each $i$ :

$$
\begin{array}{ll}
E_{\text {grid }}[i]=\frac{Q_{\text {build }}[i]-Q_{\mathrm{DCS}}[i]}{C O P[i]}-E_{\mathrm{PV}}[i] & \text { if } \frac{Q_{\text {build }}[i]-Q_{\mathrm{DCS}}[i]}{C O P[i]}-E_{\mathrm{PV}}[i]>0 \\
E_{\text {grid }}[i]=0 & \text { if } \frac{Q_{\text {build }}[i]-Q_{\mathrm{DCS}}[i]}{C O P[i]}-E_{\mathrm{PV}}[i] \leq 0
\end{array}
$$

Through Equation (1), for each time step $t$ the MPC can estimate the overall electrical energy that the system will collect from the grid from $t$ to the end of the prediction horizon $\left(t+t_{\mathrm{PH}}\right)$. The minimization algorithm of the MPC must therefore find for which indoor setpoint temperature, $T_{\text {set, }}$, the overall electricity absorbed from the grid is minimum. With a mathematical formulation, this can be written as:

$$
\text { find } T_{\text {set }}\left[t, t+t_{\mathrm{PH}}\right] \mid E_{\text {grid }}\left[t, t+t_{\mathrm{PH}}\right]=\min \left(E_{\text {grid }}\left[t, t+t_{\mathrm{PH}}\right]\right)
$$




$$
\text { s.t. } T_{\mathrm{set}}\left[t, t+t_{\mathrm{PH}}\right]=\{24.5,25.5,26.5,27.5\}^{\circ} \mathrm{C}
$$

The optimization problem described by Equation (2) belongs to the paradigm of constraint programming [53]. Referring to a general constraint satisfaction problem [54], this can be defined by a triplet $(X, D, C)$ where:

- $X=T_{\text {set }}$ is the variable of the problem;

- $D=\mathbb{Q}^{+}$is the mathematical domain of the variable, in this case the field of positive rational numbers;

- $C=\{24.5,25.5,26.5,27.5\}^{\circ} \mathrm{C}$ is the set of constraints, that in the present case are hard equality constraints defined in a finite domain.

When a constraint satisfaction problem is associated to an objective function, we are dealing with a so-called constraint optimization problem [53]. As can be noted from Equation (2) and the problem cases reported above, the $T_{\text {set }}$ value found by the MPC minimization algorithm for each time step $t$ is referred to the whole evaluation time $\left[t, t+t_{\mathrm{PH}}\right]$, and not to the current time step $t$. In other words, the setpoint temperature found by the MPC is a single, optimal average value that minimizes $E_{\text {grid }}$ in the whole evaluation time. This simplification of the optimization process was necessary in order to guarantee acceptable calculation times for the MPC. In fact, being it based on a pattern recognition ANN, the $Q_{\text {build }}$ function that appears in the objective function described by Equation (1) is a complicated nonlinear mapping of the building cooling demand, that extends the optimization process significantly. The simplification, however, does not worsen the optimization results excessively, as they are anyway bounded in the set of constraints reported in Equation (2). In summary, the optimization problem under study is defined under a limited set of equality constraints and the objective function depends on one variable only. In this case, a substitution method can be used, i.e. Equation (2) can be solved for the four allowable values of $T_{\text {set, }}$ and then the MPC can select the actual value of $T_{\text {set }}$ that minimizes $E_{\text {grid. }}$.

Figure 11 represents a block diagram that summarizes the MPC operation and its interaction with the single-family house (User 4). The house, together with the other users and the DCS, was reproduced in a TRNSYS simulation environment. On the other hand, the MPC routine was written in MATLAB as for the ANN used to predict the 
cooling demand. During the time step $t$, the User 4 sub-environment calls the MPC through a dedicated Type 155, which starts the MATLAB engine. Since the goal of the MPC is to find the indoor setpoint temperature that minimizes $E_{\text {grid }}$ defined as in Equation (1), for each time step $t$ the inputs of the MPC must be the potential free energy sources $\left(Q_{\mathrm{DCS}}\right.$ and $\left.E_{\mathrm{PV}}\right)$ and the $C O P$ of the variable-load AWHP. The quantities $Q_{\mathrm{DCS}}, E_{\mathrm{PV}}$ and $C O P$, as well as $Q_{\text {build, }}$ are not scalar values, but arrays whose dimension matches the prediction horizon $t_{\mathrm{PH}}$ chosen for the simulation. In Figure 11, this aspect is highlighted by the symbolism $\left[t, t+t_{\mathrm{PH}}\right]$. The minimization algorithm of the MPC determines the optimal $T_{\text {set }}$ value that minimizes $E_{\text {grid, }}$ according to Equation (2). Then, the value found for $T_{\text {set, }}$ along with the Boolean controls $C T R L_{\mathrm{DCS}}$ and $C T R L_{\mathrm{HP}}$ determined according to the specific problem case, are exported to the TRNSYS simulation environment. They are therefore used to solve the transient energy balance of the User 4 system for the current time step $t$.

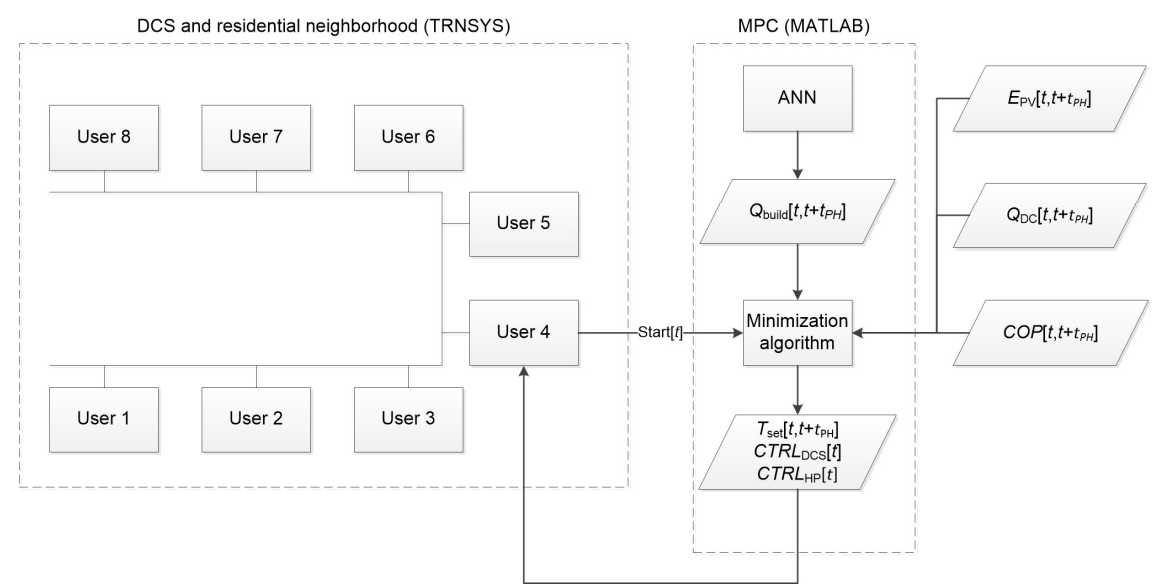

Figure 11. Block diagram of the simulation environment. For each time step $t$,

User 4 sub-environment calls the MPC routine, that determines the optimal $T_{\text {set }}$ over the prediction horizon $t_{\mathrm{PH}}$, together with the controls $C T R L_{\mathrm{DCS}}$ and $C T R L_{\mathrm{HP}}$. 


\section{Results and discussion}

As discussed in Section 2, the choice of the prediction time horizon influences the performance of an MPC. Thus, the MPC of the present study was tested over different values of the prediction horizon, in order to find the one that minimizes the electricity collected from the grid. Taking into account the typical meteorological conditions for Rome, Italy, during the cooling season (from June 01 to September 30), Figure 12 shows how the MPC performs respect to the baseline for typical values of the prediction horizon $(6,12,18,24$ hours). As can be seen, the use of the MPC allows to reduce the electricity collected from the grid regardless of the extent of the prediction horizon. However, it was found that the prediction horizon value that minimizes $E_{\text {grid }}$ is 18 hours. In this case, the MPC was able to reduce the energy absorbed from the grid by $-71 \%$. Along with the electricity consumption, in the present study the $\mathrm{CO}_{2}$ equivalent emissions of the baseline and of the MPC working at different prediction horizons were also estimated. Since electrical energy produced by the PV plant and cold thermal energy provided by the DCS were assimilated to renewable/waste sources, no carbon dioxide emission was associated to these sources. Under this assumption, the $\mathrm{CO}_{2}$ emissions of the multi-energy system are only due to the electricity drawn from the grid. Taking into account the Italian household sector, an average conversion factor equal to $352.4 \mathrm{~g}$ of $\mathrm{CO}_{2}$ equivalent for $\mathrm{kWh}$ of electrical energy was considered [55]. For the entire cooling season, the conversion factor led to an emission of about $11 \mathrm{~kg}$ of $\mathrm{CO}_{2}$ equivalent for the baseline, and of 7, 5, 3 and $7 \mathrm{~kg}$ of $\mathrm{CO}_{2}$ equivalent for the MPC with the prediction horizons considered. The trend of the carbon dioxide emissions is therefore equal to that of the electricity absorbed from the grid (Figure 12) and reflects what already discussed in Section 2, i.e. that the best prediction horizon is usually a tradeoff between a short prediction time, more precise but more limited in the prediction capability, and a long prediction time, which provides more information to the control, but whose reliability could be inferior. 


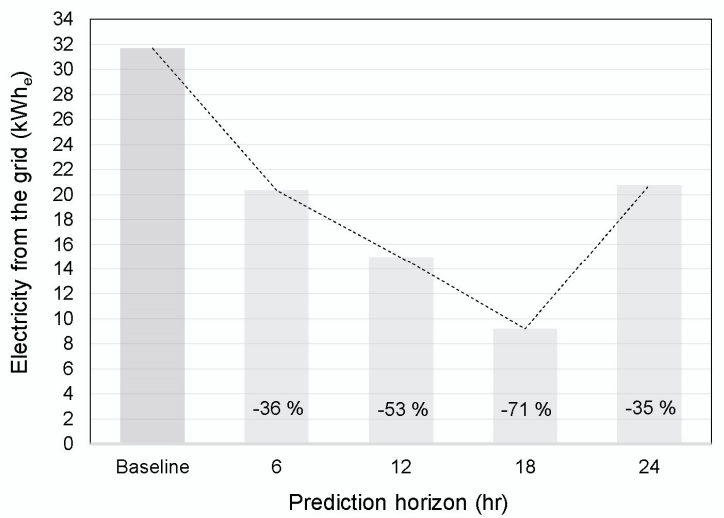

Figure 12. Electricity absorbed from the grid for different values of the prediction time horizon. The energy deviations are referred to the baseline.

Focusing on the results obtained by the MPC for a prediction horizon of 18 hours, Figure 13 reports the mix of energy sources used by User 4, subdivided for the months considered in the cooling season. In each month, the MPC prioritizes the use of the waste cold thermal energy provided by the DCS. In the periods with higher availability of solar radiation (mainly July and August), the MPC also tries to use the electricity produced by the PV plant, if available. If there is no possibility to meet the cooling demand of User 4 with the free energy sources, the MPC allows the variable-load AWHP to collect the remaining fraction of energy from the electrical grid. This fraction, however, is limited during the cooling season. In fact, the MPC has the possibility to unlock the energy flexibility of the building by adjusting the variable indoor setpoint temperature, thus allowing a pre-cooling of the building several hours before the actual request of cooling demand. 

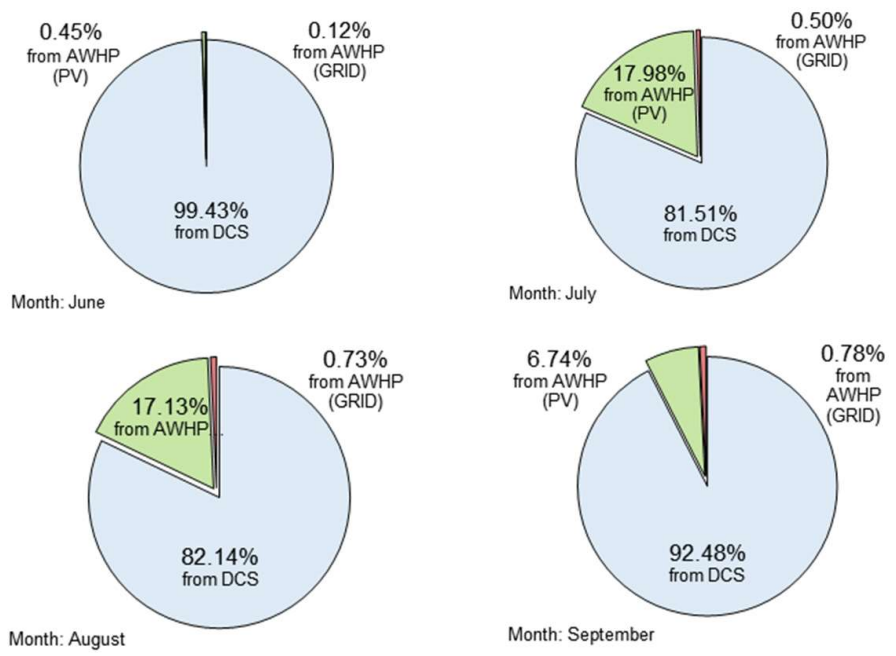

Figure 13. Use of the energy sources by User 4 with the MPC working at a prediction horizon of 18 hours.

To investigate in detail how the MPC operates, it is necessary to analyze the trend of the variable indoor setpoint temperature, as well as the availability and use of the free energy sources. Starting from the former, Figure 14 shows how indoor temperature changes for User 4 during a typical week. Referring to the baseline, it can be seen that the setpoint temperature is fixed at $25.5^{\circ} \mathrm{C}$, and the corresponding indoor temperature fluctuates in a narrow band $\left( \pm 0.5^{\circ} \mathrm{C}\right)$. In the same figure, it is possible to note that, for a prediction horizon of 18 hours, the MPC allows the setpoint temperature to vary in the range $24.5-27.5^{\circ} \mathrm{C}$. For each hour, the indoor setpoint temperature used in the local thermostat control of the building comes from the energy optimization carried out by the supervisory MPC, which tries to unlock the energy flexibility of the building. As a consequence of flexibility, there is a wider fluctuation of the actual indoor temperature. By predicting a cooling demand in the hottest hours of the day, the MPC takes advantage of the availability of waste cold thermal energy from the DCS in the morning hours and lowers the setpoint temperature to obtain a pre-cooling of the building. 


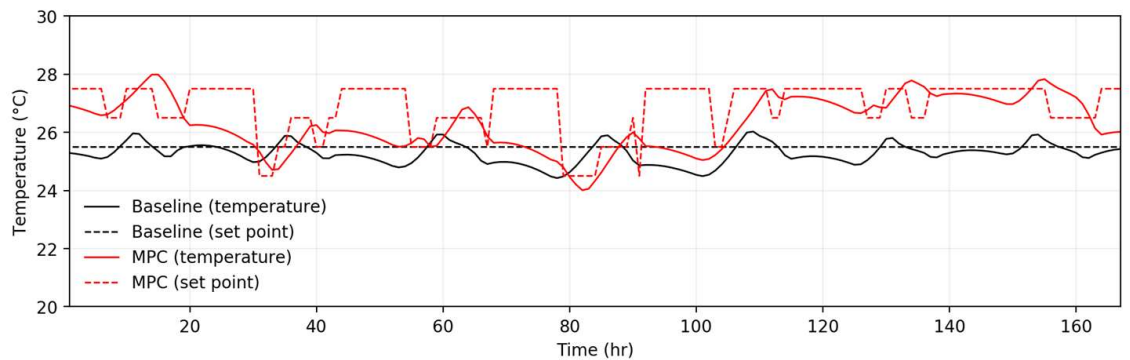

Figure 14. Indoor and setpoint temperatures during a typical week for the baseline and the MPC working at a prediction horizon of 18 hours (User 4).

Even without the MPC, the system is able to use the free energy sources available, as depicted for example in Figure 15 for the cold thermal energy drawn from the DCS. However, this is only possible when there is a temporal match between the availability of the source and the cooling demand, because in the baseline there is no possibility to use the energy flexibility of the building. Without the MPC, the baseline is not able to operate a pre-cooling of the building, thus there are periods where the operation of the AWHP cannot be avoided (as visible in the central four days of Figure 16). In this case, the only way to avoid electricity absorption from the grid relies on the availability of the solar source. When there is a match between electricity demand and production from the PV plant, there is no absorption from the grid even in the baseline. In some days, however, this condition is not met, and the multi-energy system is forced to draw electrical energy from the grid, as shown in two days of Figure 17. In these situations, the operation of the multi-energy system and the interaction between its subsystems are not optimized, leading to an inadequate exploitation of the free energy sources available. The reduction of electrical energy consumption is therefore limited, even in presence of a DCS fed with waste cold thermal energy and a PV plant. 


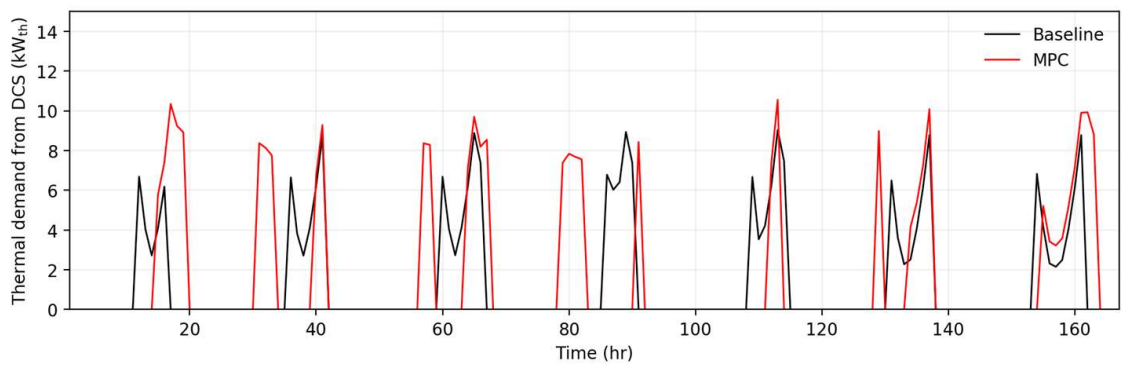

Figure 15. Cooling demand covered by the DCS during a typical week for the baseline and the MPC working at a prediction horizon of 18 hours (User 4).

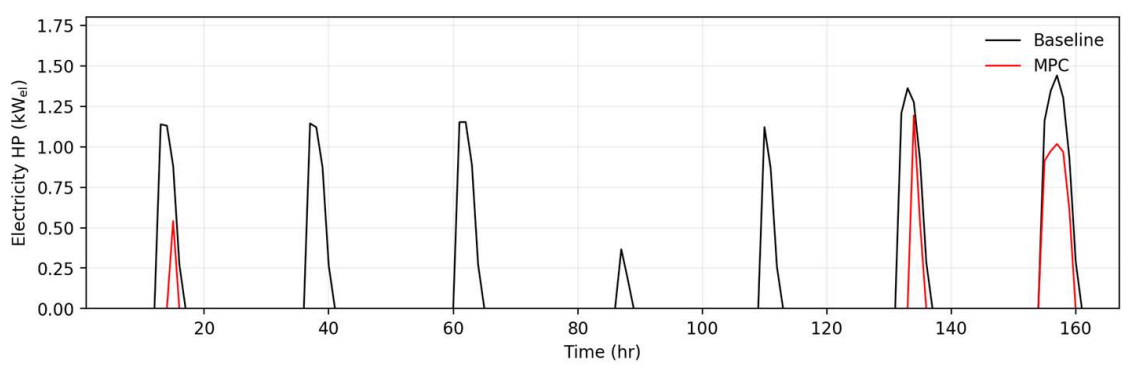

Figure 16. Electrical power used by the AWHP to meet the cooling demand of User 4 during a typical week. The curves refer to the baseline and the MPC working at a prediction horizon of 18 hours.

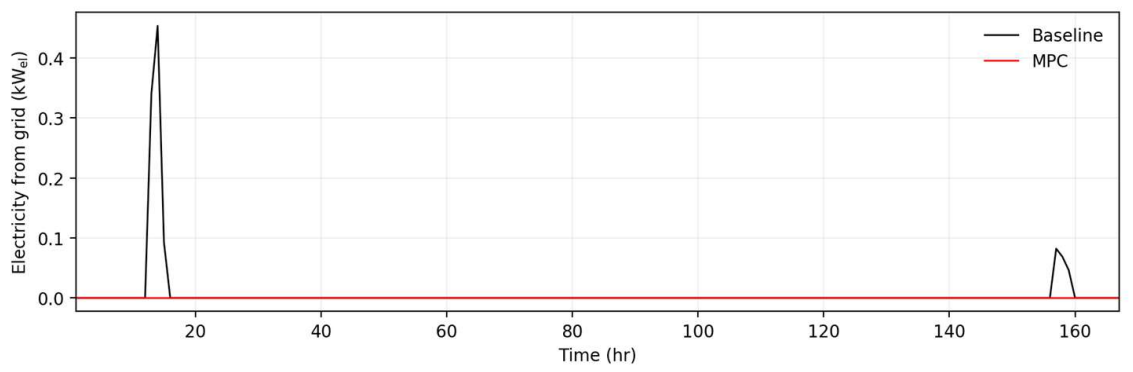

Figure 17. Electrical power drawn from the grid to meet the cooling demand of User 4 during a typical week. The curves refer to the baseline and the MPC working at a prediction horizon of 18 hours. 
The use of an MPC approach allows to reduce the overall electricity collected from the grid but, as visible in Figure 14, also leads to a wider variation of the indoor temperature. Thus, the thermal comfort level inside the building could be insufficient. To investigate this aspect, the predicted mean vote $(P M V)$ of User 4 during the cooling season was evaluated and its trend was reported in Figure 18. As can be seen, the $P M V$ trend attests a good thermal comfort level when the MPC is used: the condition $|P M V| \leq 0.5$ is not satisfied for 204 hours, that represent about the $7 \%$ of the entire cooling season considered. As a comparison, in the baseline the same condition is not satisfied for 108 hours (4\%). It is therefore possible to conclude that the MPC is also able to guarantee a good thermal comfort quality.

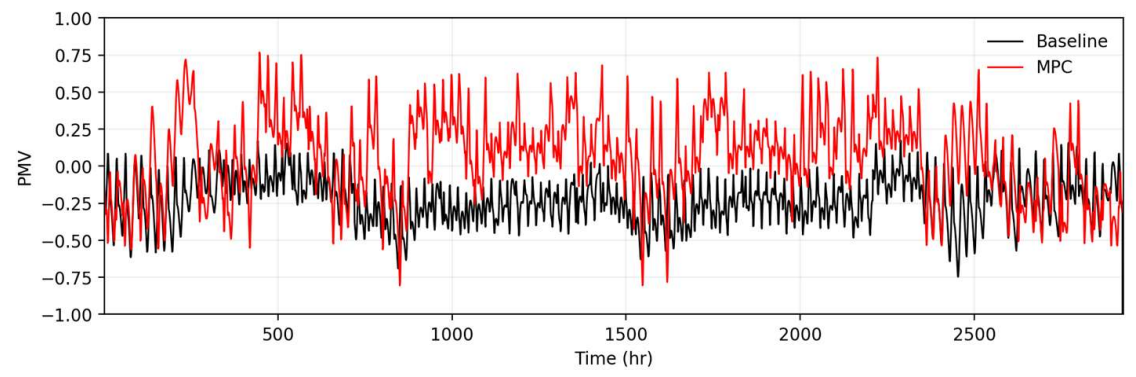

Figure 18. PMV trend of User 4 during the cooling season for the baseline and the MPC working at a prediction horizon of 18 hours.

Attempting to generalize the results of the study, it is possible to state that multienergy systems having specific interactions between their subsystems need to be carefully analyzed in order to reduce the consumption of electrical energy. The presence of RESs or waste resources only does not guarantee an optimal utilization of the free energy sources, especially if there are frequent temporal mismatches between the sources and the demand. The development and use of a dedicated supervisory MPC, able to predict both the sources and the demand in a proper prediction horizon, can help the management of the energy systems. Through the prediction, the MPC has the possibility to unlock the energy flexibility provided by the building and thus to minimize the temporal mismatches between the free energy sources and the demand. 
This control strategy should be effective in reducing electrical energy consumption even in complex, multi-energy systems. It should be also noted that MPCs based on black box models such as ANNs have the possibility to be trained again when new data are available, thus they can continuously improve the model they represent. This remarkable advantage, however, is counterbalanced by other issues, in particular a greater difficulty in training an ANN capable of managing energy flexibility properly. It is possible to deal with this issue by using, for the training of the ANN, an adequate dataset able to account for the effects of flexibility in the parameters considered; otherwise, the trained ANN would show poor performance in this regard, worsening the general performance of the ANN-based MPC.

\section{Conclusion}

This paper analyzes the energy performance of a district cooling system (DCS) providing waste cold thermal energy, obtained from a liquid-to-compressed natural gas (L-CNG) fuel station, to meet the cooling demand of a residential neighborhood comprising 8 single-family houses. Along with the cold thermal energy provided by the DCS, each house includes a variable-load air-to-water heat pump (AWHP) used as backup system. The AWHP can be powered either with the electricity produced from a photovoltaic (PV) plant or directly from the grid. One building of the residential neighborhood was allowed to be managed by a model predictive control (MPC), in order to reduce the electricity collected from the grid $\left(E_{\text {grid }}\right)$ by exploiting the energy flexibility available in the building itself. The MPC prediction algorithm is based on an artificial neural network (ANN), designed and trained to evaluate the cooling demand of that particular user. For each time step of the simulation environment, the ANNbased MPC tries to minimize $E_{\text {grid }}$ by selecting the optimal indoor setpoint temperature, which represents the flexibility parameter of the system.

Respect to the baseline case, which uses a traditional thermostatic control at fixed temperature, the results of the analysis show that the MPC is able to reduce the electricity consumption regardless of the considered prediction time horizon.

Specifically, it was found that the prediction horizon that minimizes $E_{\text {grid }}$ is equal to 18 
hours. With this value, the electricity absorbed from the grid resulted to be $-71 \%$ compared to the baseline. Despite allowing wider fluctuations of the actual indoor temperature, the MPC was also able to guarantee a good thermal comfort level; in fact, the assessment of the predicted mean vote $(P M V)$ showed that the condition $|P M V| \leq$ 0.5 is not satisfied for only the $7 \%$ of the entire cooling season considered.

The study highlighted that a multi-energy system, even if based on renewable energy and waste resources, is not completely able to reduce the consumption of electrical energy because temporal mismatches between the sources and the demand cannot be avoided. The use of a supervisory ANN-based MPC, however, can reduce the mismatches by unlocking the energy flexibility of the building, and thus lead to a minimization of electrical energy utilization. In this regard, great care should be dedicated to the training process of the ANN. In fact, it is important providing the network with data that significantly represent the case under study. In the multi-energy system proposed in this work, to correctly model the cooling demand, it was necessary to train the ANN with data based on variable indoor setpoints, condition that differs from the baseline in some extent. If provided with simple baseline data, the ANN would have shown poor performance, and the prediction of the cooling demand would have been unreliable.

\section{Funding}

This research was funded by the Italian Ministero dell'Istruzione, dell'Università e della Ricerca (MIUR) within the framework of PRIN2015 project "Clean Heating and Cooling Technologies for an Energy Efficient Smart Grid”, Prot. 2015M8S2PA.

\section{Nomenclature}

\section{Latin symbols}

COP Coefficient of Performance 


$\begin{array}{ll}\text { CTRL } & \text { Boolean control } \\ C & \text { Set of constraints of the constraint satisfaction problem } \\ D & \text { Domain of the constraint satisfaction problem } \\ E & \text { Electrical energy }\left(\mathrm{kWh}_{\mathrm{e}}\right) \\ P M V & \text { Predicted Mean Vote } \\ Q & \text { Thermal energy }\left(\mathrm{kWh}_{\mathrm{t}}\right) \\ T & \text { Temperature }\left({ }^{\circ} \mathrm{C}\right) \\ t & \text { Time }(\mathrm{hr}) \\ X & \text { Variable of the constraint satisfaction problem }\end{array}$

\section{Subscripts}

$\begin{array}{ll}\text { build } & \text { Building } \\ \text { HP } & \text { Heat pump } \\ \text { PH } & \text { Prediction horizon } \\ \text { set } & \text { Setpoint }\end{array}$

Acronyms

$\begin{array}{ll}\text { ANN } & \text { Artificial Neural Network } \\ \text { AWHP } & \text { Air-to-Water Heat Pump } \\ \text { CNG } & \text { Compressed Natural Gas } \\ \text { DSC } & \text { District Cooling System } \\ \text { DSM } & \text { Demand Side Management } \\ \text { EU } & \text { European Union } \\ \text { FCU } & \text { Fan Coil Unit } \\ \text { HVAC } & \text { Heating, Ventilation, and Air Conditioning } \\ \text { LNG } & \text { Liquified Natural Gas } \\ \text { MPC } & \text { Model Predictive Control } \\ \text { PV } & \text { Photovoltaic } \\ \text { RES } & \text { Renewable Energy Source }\end{array}$


TCL Thermostatically Controlled Load

TES Thermal Energy System

\section{References}

[1] Jakubcionis M, Carlsson J. Estimation of European Union residential sector space cooling potential. Energy Policy 2017;101:225-35.

[2] Arteconi A, Polonara F. Assessing the demand side management potential and the energy flexibility of heat pumps in buildings. Energies 2018;11:1846.

[3] Arteconi A, Mugnini A, Polonara F. Energy flexible buildings: A methodology for rating the flexibility performance of buildings with electric heating and cooling systems. Appl Energy 2019;251:113387.

[4] Zehir MA, Bagriyanik M. Demand side management by controlling refrigerators and its effects on consumers. Energy Convers Manag 2012;64:238-44.

[5] Guelpa E, Bischi A, Verda V, Chertkov M, Lund H. Towards future infrastructures for sustainable multi-energy systems: A review. Energy $2019 ; 184: 2-21$.

[6] Energy Efficiency Directive 2020.

[7] Strategic Energy Technologies Information System 2020.

[8] Gang W, Wang S, Xiao F, Gao D. District cooling systems: Technology integration, system optimization, challenges and opportunities for applications. Renew Sustain Energy Rev 2016;53:253-64.

[9] Lund H, Duic N, Østergaard PA, Mathiesen BV. Future district heating systems and technologies: On the role of smart energy systems and 4th generation district heating. Energy 2018;165:614-9.

[10] Jensen SØ, Marszal-Pomianowska A, Lollini R, Pasut W, Knotzer A, Engelmann P, et al. IEA EBC annex 67 energy flexible buildings. Energy Build 2017;155:25-34.

[11] Junker RG, Azar AG, Lopes RA, Lindberg KB, Reynders G, Relan R, et al. Characterizing the energy flexibility of buildings and districts. Appl Energy 2018;225:175-82. 
[12] Du C, Li B, Yu W, Liu H, Yao R. Energy flexibility for heating and cooling based on seasonal occupant thermal adaptation in mixed-mode residential buildings. Energy 2019;189:116339.

[13] Huang G, Wang S, Xu X. A robust model predictive control strategy for improving the control performance of air-conditioning systems. Energy Convers Manag 2009;50:2650-8.

[14] Fischer D, Madani H. On heat pumps in smart grids: A review. Renew Sustain Energy Rev 2017;70:342-57.

[15] Gholamibozanjani G, Tarragona J, De Gracia A, Fernández C, Cabeza LF, Farid MM. Model predictive control strategy applied to different types of building for space heating. Appl Energy 2018;231:959-71.

[16] Bishop CM. Neural networks and their applications. Rev Sci Instrum 1994;65:1803-32.

[17] Molina-Solana M, Ros M, Ruiz MD, Gómez-Romero J, Mart'’in-Bautista MJ. Data science for building energy management: A review. Renew Sustain Energy Rev 2017;70:598-609.

[18] Robinson C, Dilkina B, Hubbs J, Zhang W, Guhathakurta S, Brown MA, et al. Machine learning approaches for estimating commercial building energy consumption. Appl Energy 2017;208:889-904.

[19] Chan ALS, Hanby VI, Chow T-T. Optimization of distribution piping network in district cooling system using genetic algorithm with local search. Energy Convers Manag 2007;48:2622-9.

[20] Oh SJ, Ng KC, Thu K, Chun W, Chua KJE. Forecasting long-term electricity demand for cooling of Singapore's buildings incorporating an innovative airconditioning technology. Energy Build 2016;127:183-93.

[21] van der Heijde B, Fuchs M, Tugores CR, Schweiger G, Sartor K, Basciotti D, et al. Dynamic equation-based thermo-hydraulic pipe model for district heating and cooling systems. Energy Convers Manag 2017;151:158-69.

[22] Vandermeulen A, van der Heijde B, Helsen L. Controlling district heating and cooling networks to unlock flexibility: A review. Energy 2018;151:103-15.

[23] Dorotić H, Pukšec T, Duić N. Multi-objective optimization of district heating and cooling systems for a one-year time horizon. Energy 2019;169:319-28. 
[24] Arabkoohsar A, Sadi M. A solar PTC powered absorption chiller design for Co-supply of district heating and cooling systems in Denmark. Energy 2020;193:116789.

[25] Sun F, Li J, Fu L, Li Y, Wang R, Zhang S. New configurations of district heating and cooling system based on absorption and compression chillers driven by waste heat of flue gas from coke ovens. Energy 2020;193:116707.

[26] Sommer T, Sulzer M, Wetter M, Sotnikov A, Mennel S, Stettler C. The reservoir network: A new network topology for district heating and cooling. Energy 2020:117418.

[27] Jangsten M, Lindholm T, Dalenbäck J-O. Analysis of operational data from a district cooling system and its connected buildings. Energy 2020:117844.

[28] Anderson A, Rezaie B, Rosen MA. An innovative approach to enhance sustainability of a district cooling system by adjusting cold thermal storage and chiller operation. Energy n.d.;214:118949.

[29] Ferreira PM, Ruano AE, Silva S, Conceicao EZE. Neural networks based predictive control for thermal comfort and energy savings in public buildings. Energy Build 2012;55:238-51.

[30] Ruano AE, Pesteh S, Silva S, Duarte H, Mestre G, Ferreira PM, et al. The IMBPC HVAC system: A complete MBPC solution for existing HVAC systems. Energy Build 2016;120:145-58.

[31] Afram A, Janabi-Sharifi F. Supervisory model predictive controller (MPC) for residential HVAC systems: Implementation and experimentation on archetype sustainable house in Toronto. Energy Build 2017;154:268-82.

[32] Ławryńczuk M, Ocłoń P. Model Predictive Control and energy optimisation in residential building with electric underfloor heating system. Energy 2019;182:1028-44.

[33] Aoun N, Bavière R, Vallée M, Aurousseau A, Sandou G. Modelling and flexible predictive control of buildings space-heating demand in district heating systems. Energy 2019;188:116042.

[34] Saletti C, Gambarotta A, Morini M. Development, analysis and application of a predictive controller to a small-scale district heating system. Appl Therm Eng 2020;165:114558.

[35] Cox SJ, Kim D, Cho H, Mago P. Real time optimal control of district cooling system with thermal energy storage using neural networks. Appl Energy 
2019;238:466-80.

[36] Lyons B, O’Dwyer E, Shah N. Model reduction for Model Predictive Control of district and communal heating systems within cooperative energy systems. Energy 2020;197:117178.

[37] De Lorenzi A, Gambarotta A, Morini M, Rossi M, Saletti C. Setup and testing of smart controllers for small-scale district heating networks: An integrated framework. Energy 2020:118054.

[38] Mugnini A, Coccia G, Polonara F, Arteconi A. Potential of district cooling systems: A case study on recovering cold energy from liquefied natural gas vaporization. Energies 2019. https://doi.org/10.3390/en12153027.

[39] Franci T. Le prospettive del mercato italiano degli usi finali del GNL in Italia Distribuzione primaria del GNL in Italia 2017.

[40] He T, Chong ZR, Zheng J, Ju Y, Linga P. LNG cold energy utilization: $\begin{array}{llll}\text { Prospects and } & \text { challenges. }\end{array}$ https://doi.org/10.1016/j.energy.2018.12.170.

[41] Farzaneh-Gord M, Saadat-Targhi M, Khadem J. Selecting optimal volume ratio of reservoir tanks in $\mathrm{CNG}$ refueling station with multi-line storage system. Int J Hydrogen Energy 2016. https://doi.org/10.1016/j.ijhydene.2016.10.050.

[42] CELSIUS SAS, Manufacturer $\mathrm{P}$ industry equipment. Thermal fluid characteristics (Glycol Water) n.d.

[43] S.p.a. 42. Aquatechnik Group. Pre-insulated piping system for the district heating \& cooling (DHC) n.d.

[44] Doninelli M. I circuiti e i terminali degli impianti di climatizzazione (the circuits and the terminals of the air conditioning systems). Quad Caleffi n.d.

[45] Corrado V, Ballarini I, Corgnati SP. Typology Approach for Building Stock: D6.2 National scientific report on the TABULA activities in Italy. 2012.

[46] ISO UnE. Energy performance of buildings Calculation of energy use for space heating and cooling 2008:1-24.

[47] American Society of Heating $R$ and A-C, (ASHRAE) E. ASHRAE HANDBOOK FUNDAMENTALS. 1791 Tullie Circle, N.E., Atlanta, GA 30329: 2005. 
[48] Viessmann. VITOCAL 200-S AWB/AWB-AC 201.B04/.B07/ .B10 / .B13 /.B16. Commercial datasheet catalogue. 2017.

[49] GmbH HQC. Q.PRO-G3 250-265. Photovoltaic module in polycrystalline silicon. Commercial datasheet catalogue 2013.

[50] Bishop CM. Pattern recognition and machine learning. springer; 2006.

[51] Møller MF. A scaled conjugate gradient algorithm for fast supervised learning. Neural Networks 1993;6:525-33. https://doi.org/https://doi.org/10.1016/S0893-6080(05)80056-5.

[52] De Boer P-T, Kroese DP, Mannor S, Rubinstein RY. A tutorial on the crossentropy method. Ann Oper Res 2005;134:19-67.

[53] Rossi F, Van Beek P, Walsh T. Handbook of constraint programming. Elsevier; 2006.

[54] Russel S, Norvig P, others. Artificial intelligence: a modern approach. Pearson Education Limited; 2013.

[55] ENEA. KiloWattene 2015. http://www.kilowattene.enea.it/. 